\title{
Effectiveness of subcutaneous low-dose alemtuzumab and rituximab combination therapy for steroid-resistant chronic graft-versus-host disease
}

Cesar Homero Gutiérrez-Aguirre, Olga Graciela Cantú-Rodríguez, Omar David Borjas-Almaguer, Oscar González-Llano, José Carlos Jaime-Pérez, Manuel Solano-Genesta, Miguel Gómez-Guijosa, Consuelo Mancias-Guerra, Luz Tarin, and David Gómez-Almaguer

Service of Hematology, Hospital Universitario “Dr. José E. González” Universidad Autónoma de Nuevo León, Monterrey, N.L., México

Manuscript received on August 31, 2011. Revised version arrived on November 7 2011. Manuscript accepted on November 24, 2011.

\section{Correspondence:}

David Gómez-Almaguer, Service of Hematology, Hospital Universitario "Dr. José E. González" Universidad Autónoma de Nuevo León, Monterrey, N.L., México, Ave. Madero y Gonzalitos, S/N, Col. Mitras Centro, Monterrey, N.L. México. CP 64460.

Phone: international

$+5281.83486136$

and 86756718.

Fax: international +5281.8675671 .

E-mail: dr_gomez@infosel.net.mx

The online version of this article has a Supplementary Appendix.

\section{ABSTRACT}

\section{Background}

Chronic graft-versus-host disease is a common late complication of allogeneic hematopoietic stem cell transplantation. Corticosteroids are the standard initial treatment. Second-line treatment has not been well defined. We evaluated the effectiveness and safety of low doses of alemtuzumab plus low doses of rituximab in the treatment of steroid-refractory chronic graftversus-host disease.

\section{Design and Methods}

Ten men and 5 women were prospectively included in the study. All patients received one cycle of subcutaneous alemtuzumab $10 \mathrm{mg} /$ day/3 days and intravenous rituximab $100 \mathrm{mg}$ on Days $+4,+11,+18$ and +25 . The therapeutic response was measured on Days $+30,+90$ and +365 of the protocol.

\section{Results}

Median age was 41 years. The main site involved was the oral mucosa $(86.7 \%)$ followed by the eyes $(66.7 \%)$, liver $(60 \%)$, skin $(53 \%)$, lungs $(13.3 \%)$ and intestinal tract $(6.7 \%)$. The overall response was $100 \%$ at Day +30 evaluation: 10 patients $(67 \%)$ had partial remission, $5(33 \%)$ had complete remission. At Day +90 evaluation, 7 (50\%) patients had partial remission, 4 $(28 \%)$ had complete remission; 3 (21\%) had relapsed chronic graft-versus-host disease and one patient did not reach the evaluation time point. So far, 5 patients have reached the Day +365 follow-up evaluation; 2 (40\%) had partial remission, 2 had complete remission and one experienced chronic graft-versus-host disease progression. Adverse effects were mainly infections in $67 \%$ of patients; these were all quickly solved, except for one patient who died from pneumonia.

\section{Conclusions}

This combination therapy appears to be an efficacious and safe treatment for steroid-refractory chronic graft-versus-host disease. Longer follow up to determine the durability of response and survival is required (ClinicalTrials.gov: NCT01042509).

Key words: alemtuzumab, rituximab, graft-versus-host disease, hematopoietic stem cell transplant.

Citation: Gutiérrez-Aguirre CH, Cantú-Rodríguez OG, Borjas-Almaguer OD, González-Llano O, Jaime-Pérez JC, Solano-Genesta M, Gómez-Guijosa M, Mancias-Guerra C, Tarin L, and GómezAlmaguer D. Effectiveness of subcutaneous low-dose alemtuzumab and rituximab combination therapy for steroid-resistant chronic graft-versus-host disease. Haematologica 2012;97(5):717-722. doi:10.3324/haematol.2011.054577

(C)2012 Ferrata Storti Foundation. This is an open-access paper. 


\section{Introduction}

Chronic graft-versus-host disease (cGvHD) is a common late complication of allogeneic hematopoietic stem cell transplantation (allo-HSCT). It characteristically shows clinical manifestations that resemble autoimmune disorders. cGvHD may affect up to $60 \%$ of patients who undergo HLA-identical allo-HSCT and survive beyond 100 days. cGvHD affects a variety of organs, including the oral mucosa, intestinal tract, liver, eyes, lungs, bone marrow, muscles and frequently the skin. ${ }^{1,2}$ In many patients, GvHD develops despite prophylactic treatment, which often includes low doses of methotrexate combined with cyclosporine; both GvHD and this combination treatment often decreases the quality of life and increases morbidity and mortality.,4 The most common first-line treatment for $c \mathrm{GvHD}$ is steroids in combination with cyclosporine or another calcineurin inhibitor. For patients with steroidresistant cGvHD, second-line treatment is less well defined due to the lack of clinical studies. ${ }^{5}$ There are numerous single drugs or combination therapies that can be used to treat steroid-resistant $\mathrm{cGvHD}$, including calcineurin inhibitors, pulses of high doses of methylprednisolone, photopheresis, mycophenolate mofetil, immunomodulating agents like thalidomide, azathioprine, rituximab, hydroxychloroquine, imatinib, alemtuzumab, thoracoabdominal irradiation, etc. 5,6 However, most of these treatments, such as rituximab, are classified at C-2 level (recommended second-line treatment), and compounds like alemtuzumab are classified at C-4 level (experimental, used only in clinical trials or individual cases). ${ }^{5}$ Rituximab is a monoclonal anti-CD20 antibody used for treating non-Hodgkin's lymphoma and several autoimmune diseases. Rituximab causes a rapid depletion of pre-B and mature B cells which remain at low levels for 3-6 months. ' Some studies have demonstrated that rituximab is effective for $\mathrm{CGvHD}$ treatment because B cells play a role in its pathogenesis, especially in patients with immune cytopenia and skin involvement. ${ }^{8}$ Alemtuzumab, on the other hand, is an anti-CD52 IgG monoclonal antibody that demonstrates activity against $B$ cells, $T$ cells and Natural Killer cells. ${ }^{9,10}$ Currently, alemtuzumab is mainly used to treat B-cell chronic lymphocytic leukemia; however, this drug has also been used in conditioning regimens for allo-HSCT, and several reports have shown that treatment with this monoclonal antibody reduced the incidence of both acute and chronic GvHD. ${ }^{11,12}$ Information is limited on the use of alemtuzumab for cGvHD treatment and there are only studies of small series and a few case reports. ${ }^{13,14}$

A simultaneous depletion of both B cells and T cells may be an optimal treatment strategy for $c G v H D$, gaining a tighter control of the strong immune response driving cGvHD pathophysiology. Acting on this rationale, we prospectively analyzed the effect of low doses of subcutaneous alemtuzumab in combination with low doses of rituximab on 15 steroid-refractory cGvHD patients. Our goal was to determine the effectiveness and safety profile of this biological combination therapy.

\section{Design and Methods}

The study protocol was approved by the local ethics committee and all of the patients gave their written informed consent prior to the procedure. Fifteen patients who received an allograft (Online Supplementary Appendix) and had cGvHD, as defined by the 2005 $\mathrm{NIH}$ consensus criteria on the diagnosis and staging of cGvHD, were prospectively included. ${ }^{2}$ These patients had steroid-refractory $\mathrm{cGvHD}$, defined as progressive disease or lack of a response despite treatment with prednisone at $1 \mathrm{mg} / \mathrm{kg} /$ day for at least four weeks. Patients were excluded if they relapsed from their underlying disease, had active bacterial or viral infection, were pregnant, HIV-positive, or tested positive for hepatitis $C$ virus or hepatitis B surface antigen. Screening for cytomegalovirus (CMV) was performed on a serum sample and a CMV Pp65 antigenemia test prior to drug administration; patients who tested positive were excluded. Patients' characteristics are summarized in Table 1.

\section{Graft-versus-host disease diagnosis and staging}

cGvHD diagnosis was based on clinical manifestations and laboratory test results according to the NIH consensus criteria on the diagnosis and staging of $\mathrm{cGvHD} ;{ }^{2}$ the results were confirmed with a biopsy when it was necessary to rule out other diagnoses. Chronic GvHD was scored on 4 levels (0-3) according to the consensus scoring system. ${ }^{2}$ cGvHD diagnosis was confirmed only after drug reaction, infection and malignancy were excluded as the cause of the clinical manifestations.

\section{Study drug administration}

At the time of entering the study, all of the 15 patients were receiving cyclosporine $\mathrm{A}(\mathrm{Cs} \mathrm{A})$ and prednisone. When the patients initiated alemtuzumab-rituximab treatment, the prednisone dose was gradually decreased over the following 15 days and eventually stopped. The cyclosporine dose was reduced to $50 \%$ when cGvHD complete remission was achieved, independently of CsA serum levels. Alemtuzumab was administered subcutaneously on cycle Days 1-3 at a dose of $10 \mathrm{mg}$ /day. One $30 \mathrm{mg}$ alemtuzumab vial was used for each patient, and prophylactic medication was not necessary. Rituximab was given intravenously on Days +4 , $+11,+18$ and +25 of one cycle at a total dose of $100 \mathrm{mg}$ each day. Prior to rituximab administration, paracetamol and chlorpheniramine were administered as prophylactic pre-medication. The planned duration of treatment was limited to one cycle. All of the patients received prophylaxis to prevent infection, which included daily acyclovir $400 \mathrm{mg}$ during ten days a month, trimethoprim-sulfamethoxazole every $48 \mathrm{~h}$ and fluconazole $100 \mathrm{mg}$ /day. Complete blood cell count and a chemistry profile were performed every ten days for one month and subsequently every four weeks. Infection screening was performed only on patients who had clinical manifestations or laboratory test results suggesting an active infection.

\section{Response definition}

There is no simplified method for quantification of a therapeutic response to $\mathrm{cGvHD}$. The therapeutic response was based on the clinician's assessment, patients' self-report of symptom intensity, laboratory results and functional status. The therapeutic response was measured on Days $+30,+90$ and +365 of the protocol. Data obtained at each evaluation were compared to the basal data. A complete response was defined as resolution of all manifestations related to $\mathrm{cGvHD}$ in a specific organ. Partial response was defined as an improvement in at least $50 \%$ of the cGvHD manifestations. Progression was defined as an increase in symptoms, signs or laboratory test abnormalities.

\section{Results}

Fifteen consecutive patients with steroid refractory cGvHD were included in this study. Median age was 41 
Table 1. Demographic characteristics of the patients.

\begin{tabular}{|c|c|c|c|c|c|c|c|c|}
\hline Patient & Age & Sex & Diagnosis & $\begin{array}{l}\text { Chimerism } \\
(\%)\end{array}$ & $\begin{array}{l}\text { Acute GvHD } \\
\text { (grade) }\end{array}$ & $\begin{array}{l}\text { Day of } \\
\text { cGVHD } \\
\text { start* }\end{array}$ & $\begin{array}{l}\text { Months of } \\
\text { cCVVHD }\end{array}$ & $\begin{array}{l}\text { Previous cGVHD } \\
\text { treatment }\end{array}$ \\
\hline 1 & 38 & M & HL & 94 & No & 657 & 3.4 & $\mathrm{P}, \mathrm{CSA}$ \\
\hline 2 & 48 & M & MM & 95 & Skin (3) Mouth (1) & 123 & 30.8 & P, CSA \\
\hline 3 & 45 & $\mathrm{~F}$ & CML & 98 & Mouth (1) & 630 & 1.9 & $\mathrm{P}, \mathrm{CSA}$ \\
\hline 4 & 46 & M & CML & 100 & No & 81 & 127.8 & P, CSA \\
\hline 5 & 39 & M & $\mathrm{AA}$ & 92 & No & 78 & 15.5 & $\mathrm{P}, \mathrm{CSA}$ \\
\hline 6 & 35 & M & AML & 100 & No & 90 & 38.6 & $\mathrm{P}, \mathrm{CSA}$ \\
\hline 7 & 26 & M & ALL & 100 & No & 105 & 42.1 & P, CSA, ATB, RTB \\
\hline 8 & 41 & $\mathrm{~F}$ & MF & 100 & No & 192 & 28.7 & P, CSA \\
\hline 9 & 48 & $\mathrm{~F}$ & $\mathrm{AA}$ & 99 & No & 578 & 4.8 & P, CSA, ATB \\
\hline 10 & 53 & M & AML & 100 & No & 121 & 31.6 & $\mathrm{P}, \mathrm{CSA}$ \\
\hline 11 & 57 & $\mathrm{~F}$ & CML & 100 & Mouth (1) & 941 & 80.4 & $\mathrm{P}, \mathrm{CSA}$ \\
\hline 12 & 30 & M & HL & 80 & No & 105 & 15.0 & P, CSA, ATB, RTB, PUVA \\
\hline 13 & 20 & M & AML & 95 & No & 78 & 5.3 & $\mathrm{P}, \mathrm{CSA}$ \\
\hline 14 & 39 & $\mathrm{~F}$ & CML & 90 & No & 149 & 50.9 & P, CSA \\
\hline 15 & 43 & M & AML & 100 & Skin (2) Liver (1) & 172 & 77.3 & $\mathrm{P}, \mathrm{CSA}$ \\
\hline
\end{tabular}

*Days between stem cell transplantation and cGVHD start. †Months of cGVHD evolution at start of alemtuzumab-rituximab. HL: Hodgkin's lymphoma; MM: multiple myeloma; AML: acute myeloid leukemia; ALL: acute lymphoblastic leukemia; CML: chronic myeloid leukemia; AA: aplastic anemia; MF: mycosis fungoides; P: prednisone; CSA: cyclosporine; ATB: alemtuzumab; RTB: rituximab; PUVA:psoralens $(P)$ and then exposing the skin to UVA (long wave ultraviolet radiation).

years (range 20-57 years). All 10 men and 5 women had GvHD prophylaxis failure and did not respond to a combination treatment with steroids and CsA. Four patients $(27 \%)$ had acute GvHD and achieved remission with CsA and prednisone; however, these patients eventually developed cGvHD after several months and were then included in the study. Four patients had cGvHD for more than one year, and 2 of these patients had avascular necrosis of the femoral head that was related to the chronic use of steroids. Most of the patients had 2 or more organs involved including the oral mucosa $(86.7 \%)$, eyes $(66.7 \%)$, liver $(60 \%)$, skin $(53 \%)$, lungs $(13.3 \%)$ and intestinal tract $(6.7 \%)$. Alemtuzumab-rituximab therapy was initiated at a median of 31 months (range 2-128 months) after cGvHD diagnosis. Previous cGvHD treatments included CsA, steroids and phototherapy (PUVA). Three patients received alemtuzumab or rituximab as a single drug for more than 60 days prior to inclusion on the protocol; none of the patients responded to single drug treatment (Table 1). All of the patients included in this study completed the therapeutic schedule with a median follow up of 232 days (range 72-618).

The overall response was $100 \%$ at the Day +30 evaluation; 10 patients $(67 \%)$ had partial remission, and $5(33 \%)$ complete remission (Online Supplementary Tables 1-3). For the patients with complete remission, the CsA dose was gradually decreased and ultimately stopped. For the patients with partial remission, the CsA dose was reduced to $50 \%$ of its initial value. Patient 4 had diarrhea grade 1 that disappeared at Day 11 of the protocol (Table 2). At the Day +90 evaluation, 7 (50\%) patients had a partial response, $4(28 \%)$ had a complete response, $3(21 \%)$ had relapsed cGvHD and one patient had not yet reached Day 90 post treatment. One patient (Patient 6) who had achieved cGvHD partial remission had a leukemia relapse (acute promyelocytic leukemia) and received a second allo-HSCT; this patient achieved complete remission without GvHD. Of the patients with relapsed cGvHD who restarted steroid treatment, one received a second cycle of alemtuzumab-rituximab treatment and achieved a second partial remission (Patient 14), and 2 (Patients 3 and 13) received four monthly doses of $100 \mathrm{mg}$ rituximab and achieved complete remission (Table 2). Currently, only 5 patients are available to evaluate the Day +365 follow up; 2 of them ( $40 \%$ ) have a partial response, 2 have a complete response and one is in progression of $\mathrm{cGvHD}$ (Table 2).

Acute side effects of alemtuzumab administration occurred in only one patient who had fever and chills after the third dose; these appeared $30 \mathrm{~min}$ after alemtuzumab administration and disappeared after administration of acetaminophen. Acute side effects of rituximab occurred in 7 patients during intravenous infusion of the drug, including chills in 4, rash in 2 and fever in one patient. Most of the side effects occurred during the first rituximab infusion and disappeared after the infusion velocity was decreased and $100 \mathrm{mg}$ of hydrocortisone was co-administered. The late side effects of the therapy were mainly infectious, including laryngitis, sinusitis, pneumonia, urinary tract infection and oral herpes simplex virus infection in one patient each, bronchitis in 2, and reactivation of cytomegalovirus in 3 patients; acute promyelocytic leukemia relapse was observed in one patient once he achieved complete cGvHD remission. Patient 10 (Table 2) had grade 2 lung cGvHD manifested by shortness of breath after walking on flat ground. This symptom disappeared at Day 35 of the protocol. However, this patient later had pneumonia and died at protocol Day 142 with partial cGvHD remission. The isolated infectious agent was identified as Rhodococcus equi. The 3 patients with CMV infection responded well to valganciclovir.

Fourteen of the 15 patients are still alive at a median follow up of 232 days (Figure 1). 
Table 2. Outcome of therapy.

\begin{tabular}{|c|c|c|c|c|c|c|c|c|c|c|c|c|c|c|c|c|}
\hline \multirow[t]{2}{*}{ Patient } & \multirow[t]{2}{*}{$\begin{array}{l}\text { End of } \\
\text { treatment }\end{array}$} & \multirow[t]{2}{*}{$\begin{array}{l}90 \\
\text { days }\end{array}$} & \multirow[t]{2}{*}{$\begin{array}{l}365 \\
\text { days }\end{array}$} & \multicolumn{5}{|c|}{$\begin{array}{c}\text { Chronic GVHD } \\
(0-4)^{2}\end{array}$} & \multicolumn{5}{|c|}{$\begin{array}{l}\text { Maximal } \\
\text { response }\end{array}$} & \multirow[t]{2}{*}{ LAE } & \multirow[t]{2}{*}{ FU } & \multirow[t]{2}{*}{$\begin{array}{l}\text { Current } \\
\text { status }\end{array}$} \\
\hline & & & & s & m/G॥ & 1 & e & lu & s & m/G^ & I & e & lu & & & \\
\hline 1 & PR & PR & * & 2 & 1 & 1 & & & 1 & 1 & 1 & & & No & 88 & Alive \\
\hline 2 & PR & PR & $*$ & 1 & 2 & & & & 1 & 1 & & & & No & 199 & Alive \\
\hline 3 & PR & $\mathrm{P} \dagger$ & $*$ & & 2 & 2 & 1 & & & 0 & 0 & 0 & & UTI & 272 & Alive \\
\hline 4 & PR & $*$ & $*$ & 2 & $1 / 1^{\wedge}$ & 2 & 2 & & 1 & $0 / 0^{\wedge}$ & 0 & 2 & & No & 72 & Alive \\
\hline 5 & CR & PR & PR & 3 & 1 & 3 & & & 0 & 0 & 0 & & & CMV & 367 & Alive \\
\hline 6 & PR & PR & * & & 2 & 1 & 1 & & & 1 & 0 & 1 & & MDR & 177 & Alive \\
\hline 7 & CR & CR & * & & 1 & 1 & 3 & & & 0 & 0 & 0 & & SI, HS & 305 & Alive \\
\hline 8 & PR & PR & $\mathrm{P}^{\ddagger}$ & 3 & 1 & & 2 & & 1 & 0 & & 2 & & CMV, LA & 618 & Alive \\
\hline 9 & PR & PR & CR & 2 & 2 & & & & 0 & 0 & & & & $\mathrm{BR}$ & 479 & Alive \\
\hline 10 & PR & PR & $*$ & 1 & 1 & 1 & 2 & 2 & 0 & 0 & 1 & 1 & 0 & CMV, Pneu & 142 & Dead \\
\hline 11 & CR & CR & $*$ & 2 & & & & & 0 & & & & & No & 232 & Alive \\
\hline 12 & CR & CR & $*$ & & 2 & 2 & 1 & & & 0 & 0 & 0 & & No & 286 & Alive \\
\hline 13 & PR & $\mathrm{P}^{\dagger}$ & $*$ & & 1 & 2 & 1 & & & 1 & 1 & 1 & & No & 197 & Alive \\
\hline 14 & PR & $\mathrm{P}^{\ddagger}$ & PR & & 1 & & 3 & 1 & & 0 & & 1 & 1 & BR & 411 & Alive \\
\hline 15 & CR & CR & CR & 2 & 2 & & 2 & & 0 & 0 & & 0 & & No & 225 & Alive \\
\hline
\end{tabular}

Chronic GVHD was scored in 4 levels (0-3) according to the consensus scoring system ${ }^{2} .{ }^{*}$ Point of evaluation not reached. 'Received 4 doses of monthly rituximab, 100 mg achieving complete remission. Received a second cycle of alemtuzumab-rituximab achieving partial remission. PR: partial response; CR: complete response; P: progression; LAE: late adverse event; FU: follow up in days; s: skin; m: mouth; GI^: gastrointestinal tract; l: liver; e: eye; lu: lung; UTI: urinary tract infection; sI: sinusitis; HS: herpes simplex, LA: laringytis, BR: bronchitis, Pneu: pneumonia; MDR: malignant disease relapsed; CMV: cytomegalovirus.

\section{Discussion}

Previous studies have shown that both alemtuzumab and rituximab have therapeutic activity on different immunological diseases, and both have been used in an attempt to reduce the incidence of GvHD. ${ }^{15,16}$ However, there have been no reports of a combination of these drugs in the treatment of cGvHD. In a previous study, we used alemtuzumab to treat 18 patients with acute GvHD (aGVHD) who did not respond to high doses of steroids; most of the patients $(83 \%)$ demonstrated a complete or partial response. ${ }^{13}$ Recently, Schub et al. obtained similar results with 18 patients. ${ }^{15}$ Alemtuzumab treatment for cGvHD has only been reported in small studies and a few case reports. Ruiz-Argüelles et al. described a patient with extensive cutaneous cGvHD that was resistant to numerous lines of treatment; this patient was treated monthly with alemtuzumab and achieved complete remission after seven months. ${ }^{14}$ However, rituximab is more commonly used for cGvHD treatment than alemtuzumab. Several reports have described the efficacy of rituximab for treatment of cGvHD-associated immune cytopenia and cutaneous manifestations. ${ }^{8}$ Teshima et al. described $7 \mathrm{cGvHD}$ patients who were treated weekly with a full $375 \mathrm{mg} / \mathrm{m}^{2}$ dose of rituximab for four weeks; the treatment improved immune hemolytic anemia, thrombocytopenia, and mild skin and oral lesions in most of the patients, but had no effect on severe cutaneous or ocular manifestations. ${ }^{17}$ Most studies have shown an overall response between 43 and $83 \% .{ }^{17-22}$ A meta-analysis by Kharfan-Dabaja et al. reported an overall rituximab response of $66 \%$, with improvements mainly in the skin $(60 \%)$, oral mucosa $(36 \%)$, hepatic $(29 \%)$, gastrointestinal $(31 \%)$ and pulmonary lesions $(30 \%)^{23}$

The optimal rituximab dose for immune-mediated hematologic disorders has not been established. In most

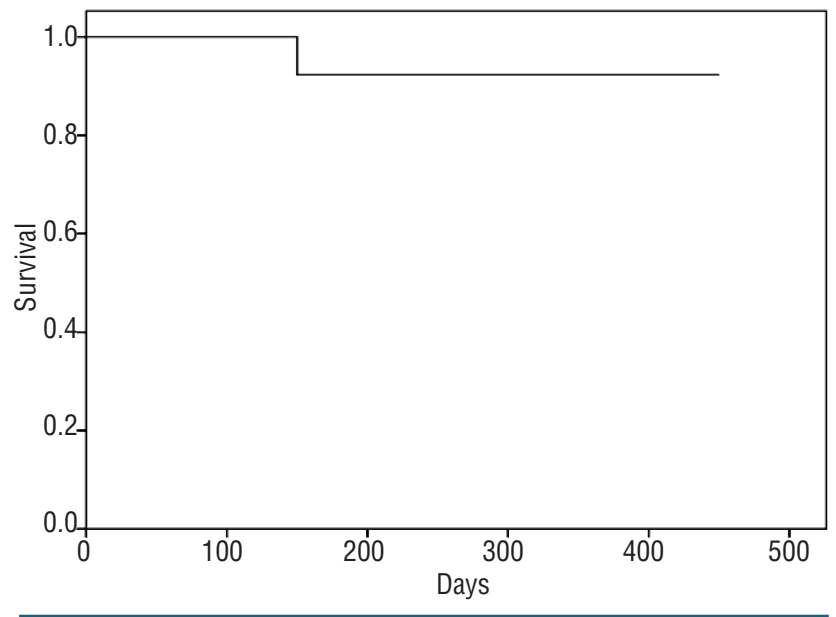

Figure 1. Overall survival of all patients.

studies, the doses are similar to those for non-Hodgkin's lymphoma. ${ }^{24}$ However, because the number of lymphocytes in cGvHD is expected to be lower, lower doses of the monoclonal antibodies may be required. Zaja et al. demonstrated that low-dose rituximab (100 mg weekly) can produce significant and durable responses which are associated with B-cell depletion in patients with autoimmune cytopenias. ${ }^{25,26}$ Thus, we assessed the therapeutic benefit of a low-dose combination of subcutaneously administered alemtuzumab and rituximab.

In our study, we used combined alemtuzumab-rituximab to reduce both B- and T-lymphocyte activity and reduce the clinical manifestations of $\mathrm{cGvHD}$. This combi- 
nation has previously been used to treat chronic lymphocytic leukemia. ${ }^{27}$ Furthermore, our group has successfully used this combination to treat autoimmune cytopenias; patients responded well and no toxicities were reported. ${ }^{28}$ In the present study, the maximal response occurred early after patients finished their treatment with the drug combination producing an overall response rate of $100 \%$ at the Day +30 evaluation; 10 patients achieved a partial remission $(67 \%)$ and 5 a complete remission $(33 \%)$. The clinical manifestations of $\mathrm{cGvHD}$ improved faster than expected; this allowed us to stop prednisone treatment without complications in all of the patients. The number of lymphocytes noticeably decreased at this point and slowly increased over time. At the Day +90 evaluation, some changes were observed in the response index. Three patients with previous partial remission showed cGvHD progression, despite a low lymphocyte count $(<500 \mathrm{~K} / \mu \mathrm{L})$; however, these 3 patients responded well to a second cycle of alemtuzumab-rituximab or to monthly rituximab treatment, as described above. It is important to note that $\mathrm{cGvHD}$ progression in these 3 patients may be related to a decrease in alemtuzumab-rituximab therapeutic activity and changes in the dose of immunosuppressive therapy. This finding should form the basis for better strategies to prevent GvHD progression.

Currently, 5 patients have survived 365 days for followup evaluation; one showed cGvHD progression with skin involvement indicated by pigmentary changes and sclerotic lesions. The patient received a second alemtuzumab-rituximab cycle and eventually achieved partial remission.

Acute adverse events during alemtuzumab-rituximab delivery were mild and quickly solved in all cases. Several studies have indicated that alemtuzumab and rituximab treatment predisposes the patient to opportunistic infections. ${ }^{15,29-33}$ Alemtuzumab has been associated with infections such as CMV, adenovirus and toxoplasmosis. ${ }^{15}$ Park et al. reported a CMV infection rate of $41.6 \%$ and a $90 \%$
CMV infection recurrence rate in 12 patients who received an alemtuzumab-based conditioning regimen for alloHSCT. ${ }^{34}$ Treatment with rituximab has also been associated with viral and opportunistic infections; Kimby reported a $30 \%$ incidence of infection in patients who received rituximab. In our study, the incidence of infection was $67 \%$; however, most of the infections were grade 2 and were resolved in an outpatient setting. One patient died from pneumonia caused by a Rhodococcus equi infection; this is an anaerobic, gram-positive coryneform bacterium that is an opportunistic pathogen which mainly infects HIV-positive patients. ${ }^{35}$ A number of additional factors in our patients may predispose them to diverse infections. The ingestion of additional medications, the effect of $\mathrm{cGvHD}$, as well as other medical problems may influence the patient's immune response. All of the patients included in this study had previously been taking steroids and CsA over a long period of time; this chronic immunosuppression may have made the patients more susceptible to infection.

In conclusion, low-dose alemtuzumab-rituximab combination therapy appears to be an efficacious and safe treatment for steroid-refractory cGvHD. Longer follow up is needed to determine the durability of response and survival. Furthermore, additional low monthly doses of rituximab may extend this response. Future studies assessing the benefits of low or conventional doses of rituximab for maintenance are needed to assess the long-term efficacy.

\section{Authorship and Disclosures}

The information provided by the authors about contributions from persons listed as authors and in acknowledgments is available with the full text of this paper at www. haematologica.org.

Financial and other disclosures provided by the authors using the ICMJE (Www.icmje.org) Uniform Format for Disclosure of Competing Interests are also available at www.haematologica.org.

\section{References}

1. Sullivan KM, Agura E, Anasetti C, Appelbaum F, Badger C, Bearman S, et al. Chronic graft-versus-host disease and other late complications of bone marrow transplantation. Semin Hematol. 1991;28(3):250-9.

2. Filipovich $A H$, Weisdorf $D$, Pavletic S, Socie G, Wingard JR, Lee SJ, et al. National Institutes of Health consensus development project on criteria for clinical trials in chronic graft-versus-host disease: I. Diagnosis and staging working group report. Biol Blood Marrow Transplant. 2005;11(12):945-56.

3. Lee SJ. New approaches for preventing and treating chronic graft-versus-host disease. Blood. 2005;105(11):4200-6.

4. Bolanos-Meade J, Vogelsang GB. Chronic graft-versus-host disease. Curr Pharm Des. 2008;14(20):1974-86.

5. Wolff D, Schleuning M, von Harsdorf S, Bacher U, Gerbitz A, Stadler M, et al. Consensus Conference on Clinical Practice in Chronic GVHD: Second-Line Treatment of Chronic Graft-versus-Host Disease. Biol Blood Marrow Transplant. 2011;17(1):1-17.

6. Wolff D, Steiner B, Hildebrandt G, Edinger M, Holler E. Pharmaceutical and cellular strategies in prophylaxis and treatment of graft-versus-host disease. Curr Pharm Des. 2009;15(17):1974-97.

7. Kimby E. Tolerability and safety of rituximab (MabThera). Cancer Treat Rev. 2005; 31(6):456-73.

8. Kharfan-Dabaja MA, Bazarbachi A Emerging role of CD20 blockade in allogeneic hematopoietic cell transplantation. Biol Blood Marrow Transplant. 2010;16 (10):1347-54.

9. Ho VT, Cutler C. Current and novel therapies in acute GVHD. Best Pract Res Clin Haematol. 2008;21(2):223-37.

10. Christian BA, Lin TS. Antibody therapy for chronic lymphocytic leukemia. Semin Hematol. 2008;45(2):95-103.

11. Kottaridis PD, Milligan DW, Chopra R, Chakraverty RK, Chakrabarti S, Robinson S, et al. In vivo CAMPATH-1H prevents graftversus-host disease following nonmyeloablative stem cell transplantation. Blood. 2000;96(7):2419-25.

12. Chakraverty R, Orti G, Roughton M, Shen J, Fielding A, Kottaridis P, et al. Impact of in vivo alemtuzumab dose before reduced intensity conditioning and HLA-identical sibling stem cell transplantation: pharmacokinetics, GVHD, and immune reconstitu- tion. Blood. 2010;116(16):3080-8

13. Gomez-Almaguer D, Ruiz-Arguelles GJ, del Carmen Tarin-Arzaga L, Gonzalez-Llano O, Gutierrez-Aguirre $\mathrm{H}$, Cantu-Rodriguez $\mathrm{O}$, et al. Alemtuzumab for the treatment of steroid-refractory acute graft-versus-host disease. Biol Blood Marrow Transplant. 2008;14(1):10-5.

14. Ruiz-Arguelles GJ, Gil-Beristain J, Magana M, Ruiz-Delgado GJ. Alemtuzumabinduced resolution of refractory cutaneous chronic graft-versus-host disease. Biol Blood Marrow Transplant. 2008;14(1):7-9.

15. Schub N, Gunther A, Schrauder A, Claviez A, Ehlert C, Gramatzki M, et al. Therapy of steroid-refractory acute GVHD with CD52 antibody alemtuzumab is effective. Bone Marrow Transplant. 2011;46(1):143-7.

16. Martinez C, Solano C, Ferra C, Sampol A Valcarcel D, Perez-Simon JA. Alemtuzumab as treatment of steroid-refractory acute graft-versus-host disease: results of a phase II study. Biol Blood Marrow Transplant. 2009;15(5):639-42.

17. Teshima T, Nagafuji K, Henzan $H$, Miyamura K, Takase K, Hidaka M, et al. Rituximab for the treatment of corticosteroid-refractory chronic graft-versus-host disease. Int J Hematol. 2009;90(2):253-60. 
18. Canninga-van Dijk MR, van der Straaten HM, Fijnheer R, Sanders CJ, van den Tweel JG, Verdonck LF. Anti-CD20 monoclonal antibody treatment in 6 patients with therapy-refractory chronic graft-versus-host disease. Blood. 2004;104(8):2603-6.

19. Cutler C, Miklos D, Kim HT, Treister N, Woo SB, Bienfang D, et al. Rituximab for steroid-refractory chronic graft-versus-host disease. Blood. 2006;108(2):756-62.

20. Okamoto M, Okano A, Akamatsu S, Ashihara $\mathrm{E}$, Inaba $\mathrm{T}$, Takenaka $\mathrm{H}$, et al. Rituximab is effective for steroid-refractory sclerodermatous chronic graft-versus-host disease. Leukemia. 2006;20(1):172-3.

21. Zaja F, Bacigalupo A, Patriarca F, Stanzani M, Van Lint MT, Fili C, et al. Treatment of refractory chronic GVHD with rituximab: a GITMO study. Bone Marrow Transplant. 2007;40(3):273-7.

22. Mohty M, Marchetti N, El-Cheikh J, Faucher C, Furst S, Blaise D. Rituximab as salvage therapy for refractory chronic GVHD. Bone Marrow Transplant. 2008;41(10):909-11.

23. Kharfan-Dabaja MA, Mhaskar AR, Djulbegovic B, Cutler C, Mohty M, Kumar A. Efficacy of rituximab in the setting of steroid-refractory chronic graft-versus-host disease: a systematic review and metaanalysis. Biol Blood Marrow Transplant. 2009;15(9):1005-13.

24. Dierickx D, Delannoy A, Saja K, Verhoef G, Provan D. Anti-CD20 monoclonal antibod- ies and their use in adult autoimmune hematological disorders. Am J Hematol. 2011;86 (3):278-91.

25. Provan D, Butler T, Evangelista MI Amadori S, Newland AC, Stasi R. Activity and safety profile of low-dose rituximab for the treatment of autoimmune cytopenias in adults. Haematologica. 2007;92(12):1695-8.

26. Zaja F, Battista ML, Pirrotta MT, Palmieri S, Montagna M, Vianelli N, et al. Lower dose rituximab is active in adults patients with idiopathic thrombocytopenic purpura. Haematologica. 2008;93(6):930-3.

27. Nabhan C, Patton D, Gordon LI, Riley MB, Kuzel T, Tallman MS, et al. A pilot trial of rituximab and alemtuzumab combination therapy in patients with relapsed and/or refractory chronic lymphocytic leukemia (CLL). Leuk Lymphoma. 2004;45(11):226973

28. Gomez-Almaguer D, Solano-Genesta M Tarin-Arzaga L, Herrera-Garza JL, CantuRodriguez OG, Gutierrez-Aguirre $\mathrm{CH}$, et al. Low-dose rituximab and alemtuzumab combination therapy for patients with steroid-refractory autoimmune cytopenias. Blood. 2010;116(23):4783-5.

29. Lund FE, Hollifield M, Schuer K, Lines JL Randall TD, Garvy BA. B cells are required for generation of protective effector and memory CD4 cells in response to Pneumocystis lung infection. J Immunol. 2006;176(10):6147-54
30. Kelesidis T, Daikos G, Boumpas D, Tsiodras $S$. Does rituximab increase the incidence of infectious complications? A narrative review. Int J Infect Dis. 2011;15(1):e2-16.

31. Aksoy S, Harputluoglu H, Kilickap S, Dede DS, Dizdar O, Altundag K, et al. Rituximabrelated viral infections in lymphoma patients. Leuk Lymphoma. 2007;48(7):130712

32. Sfikakis PP, Souliotis VL, Fragiadaki KG, Moutsopoulos HM, Boletis JN Theofilopoulos AN. Increased expression of the FoxP3 functional marker of regulatory cells following B cell depletion with rituximab in patients with lupus nephritis. Clin Immunol. 2007;123(1):66-73.

33. Sfikakis PP, Boletis JN, Lionaki S, Vigklis V, Fragiadaki KG, Iniotaki $\mathrm{A}$, et al. Remission of proliferative lupus nephritis following $B$ cell depletion therapy is preceded by downregulation of the $T$ cell costimulatory molecule CD40 ligand: an open-label trial. Arthritis Rheum. 2005;52(2):501-13

34. Park SH, Choi SM, Lee DG, Choi JH, Yoo $\mathrm{JH}$, Kim SH, et al. Infectious complications associated with alemtuzumab use for allogeneic hematopoietic stem cell transplantation: comparison with anti-thymocyte globulin. Transpl Infect Dis. 2009;11(5):413-23.

35. Drancourt M, Bonnet E, Gallais H, Peloux Y Raoult D. Rhodococcus equi infection in patients with AIDS. J Infect. 1992;24(2):123 31. 